\title{
A tale of three theories: Feyerabend and Popper on progress and the aim of science
}

\author{
Luca Tambolo \\ Department of Humanistic Studies, University of Trieste, c/o via Casona, 7, 40043 Marzabotto, Italy
}

\section{A R T I C L E I N F O}

\section{Article history:}

Received 3 November 2014

Received in revised form

14 February 2015

Available online

\section{Keywords:}

Feyerabend;

Popper;

Scientific progress;

Aim of science;

Theoretical pluralism;

Approximation to the truth

\begin{abstract}
A B S T R A C T
In this paper, three theories of progress and the aim of science are discussed: $(i)$ the theory of progress as increasing explanatory power, advocated by Popper in The logic of scientific discovery (1935/1959); (ii) the theory of progress as approximation to the truth, introduced by Popper in Conjectures and refutations (1963); (iii) the theory of progress as a steady increase of competing alternatives, which Feyerabend put forward in the essay "Reply to criticism. Comments on Smart, Sellars and Putnam" (1965) and defended as late as the last edition of Against method (1993). It is argued that, contrary to what Feyerabend scholars have predominantly assumed, Feyerabend's changing attitude towards falsificationism-which he often advocated at the beginning of his career, and vociferously attacked in the 1970s and 1980s-must be explained by taking into account not only Feyerabend's very peculiar view of the aim of science, but also Popper's changing account of progress.
\end{abstract}

(ㄷ) 2015 Elsevier Ltd. All rights reserved.

When citing this paper, please use the full journal title Studies in History and Philosophy of Science

\section{Introduction}

Paul Feyerabend's changing attitude towards falsificationism is a much debated issue within the historiography of the Popperian school in philosophy of science. As is well-known, Feyerabend made a name for himself by passionately advocating the Popperian outlook - a pretty remarkable instance being his lectures entitled Knowledge without foundations (1962a), which repeat (in some passages almost verbatim) large parts of Karl Popper's famous essay "Back to the Presocratics" (1959). At some point in the 1960s, however, Feyerabend turned his back on his former mentor, and in the 1970s and 1980s he became a vociferous-perhaps the most vociferous-critic of falsificationism.

Conflicting accounts of such turn-and of the later Feyerabend's rageful replies to those who dared to mention his previous embrace of Popper's ideas-have been offered (see Collodel, forthcoming, for a state-of-the-art discussion of the issue). To name but two examples, John Watkins has suggested that the later Feyerabend's derogatory remarks on falsificationism were due to his desire to

E-mail address: Itambolo@gmail.com. cover up an "unwanted indebtedness to Popper" (2000, p. 49), while Eric Oberheim has forcefully argued that, although Feyerabend used very freely some of Popper's ideas, he rejected falsificationism as early as the beginning of the 1960s and he "was never a member of the Popperian school" (2006, p. 78; see also Hoyningen-Huene \& Oberheim, 2000). As these examples show, there is a continued disagreement between, on the one hand, interpreters who view the early Feyerabend as someone striving to contribute to the development of Popper's research program and, on the other hand, interpreters who argue that as early as in the first half of the 1960s he aimed at proposing a theory of science which would eventually displace falsificationism. In what follows, we shall remain neutral with respect to such debate: the main aim of the present paper is, more modestly, to point out that interpreters have oftentimes taken falsificationism to be a kind of fixed anchorage in the reconstruction of Feyerabend's trajectory. To put it differently, it has often been assumed that Popper's philosophy provides a good-if not the ideal-background against which to reconstruct Feyerabend's work, among other things in view of the fact that falsificationism is a fixed system of ideas to which in different moments Feyerabend reacted, not without idiosyncrasies, in different ways. 
There is, of course, a clearly identifiable set of ideas constituting the hardcore of falsificationism that Popper never relinquished, among which the view that the method of conjectures and refutations, capturing the essence of good science, promotes progress. Nevertheless, Feyerabend scholars seem to have generally underestimated an important change which took place within Popper's philosophy between the end of the 1950s and the early 1960s, and which concerned axiological matters. More specifically, in The logic of scientific discovery Popper had defended a theory of science in which, as he remarked, "it is possible to avoid using the concepts 'true' and 'false'" (2002a [1935/1959], p. 273), and progress is viewed as a matter of finding corroborated theories exhibiting increasing explanatory and predictive power. Subsequently, in Chapter 10 of Conjectures and refutations (1963) he defended the view that scientific progress can be accounted for in terms of the increasing approximation to the truth of our theories, and was the first to put forward a formal explication of the notion of verisimilitude (or, equivalently, truthlikeness). Feyerabend was never willing to embrace Popper's second theory of progress, which conflicts with the theory of progress as a steady increase of competing alternatives that do not converge towards the truth-a theory that he put forward in the seminal essay "Reply to criticism. Comments of Smart, Sellars and Putnam" (1981c [1965]) and defended as late as the last edition of Against method (1993). As we shall argue, when the attempt is made to explain Feyerabend's changing attitude towards falsificationism, an accurate account ought to include not only Feyerabend's move away from Popper's ideas, but also Popper's move away from his own originary view of the aim of science.

The focus of our discussion will then be on the three theories of progress and the aim of science alluded to in the title of this paper. In Section 2, after a cursory recap of the basic tenets of falsificationism, Popper's two theories of progress will be introduced. In Section 3, as a way of preparation for the analysis of Feyerabend's theory of progress, his pluralistic model of theory testing, revolving around the claim that a severe test of a theory $T$ requires to take into consideration not only the available evidence, but also alternatives to $T$, will be illustrated. A special emphasis will be put on the mixed standing of Feyerabend's views on theory testing and proliferation, which although showcasing his Popperian ancestry (as recently emphasized by Bschir, forthcoming), also led him, by the mid1960s, outside the falsificationist orthodoxy. In Section 4, Feyerabend's theory of progress as a steady increase of competing alternatives, wedded to his views on theory testing and proliferation, will be analyzed. In Section 5, some brief concluding remarks will be offered.

\section{Popper's two theories of progress}

The issue of scientific progress always played a central role within the philosophy of Popper, who famously took the growth of knowledge to be the most important problem of epistemology-one which, he claimed, "can be studied best by studying the growth of scientific knowledge" (2002a [1935/1959], p. XIX). As we shall see, in different moments he put forward two different theories of progress and the aim of science; nevertheless, Popper always maintained that scientific inquiry ought to proceed according to the principles of his proposed alternative to the inductivist view of scientific method, i.e., the method of conjectures and refutations.

According to Popper, the inductivist claim that scientific inquiry takes off with the accumulation of observations, from which theories are then inductively inferred, is plainly wrong: all life is problem solving, and inquiry in science, not unlike in everyday life, arts, politics, etc., is triggered by the researcher's attempt to solve some problem by putting forward a theory, hypothesis, or conjecture. However, there is one feature that distinguishes the theories belonging to the domain of empirical science: scientific theories can conflict with experience in such a way that experience can prove them false. The basic tenet of falsificationism is then the view that the falsifiability of theories provides a criterion of demarcation-the falsifiability criterion-which allows one to tell science from non-science.

More precisely, let a basic-statement be a statement describing a singular fact, for instance, the fact that a certain swan is black. According to Popper's criterion of demarcation, a theory $T$ - for instance, the theory according to which all swans are white-is scientific iff there are basic-statements with which $T$ is incompatible, or equivalently, that are forbidden by $T$, and such that, if they were true, $T$ would be false. Such basic-statements are called by Popper the 'potential falsifiers' of $T$, and constitute its 'empirical content'-that is, the amount of information concerning the world conveyed by $T$. The greater the empirical content of a theory $T$, the more interesting $T$ is: a theory which is incompatible with many basic-statements and which, besides explaining already known facts, also makes surprising predictions, runs the risk of being falsified because it says many things about the world, and therefore qualifies, in Popper's jargon, as a bold conjecture.

Another basic tenet of falsificationism is that, once a theory has been proposed, scientists ought to severely test it, aiming at its refutation. The tests are performed by deducing from $T$-in conjunction with the so-called 'background knowledge'- predictions that are then confronted with the basic-statements accepted by the scientific community, which describe the available evidence (that is, basically, the observations and the results of experiments). If the predictions deduced from $T$ are compatible with such basicstatements, $T$ is said to have been corroborated by experience. However, according to Popper one can never attribute a positive probability to a universal theory, no matter how well corroborated: scientists embrace a corroborated theory as a satisfactory solution to the problem at hand only provisionally and tentatively, and proceed to subject such solution to further, more severe, tests. If the predictions deduced from $T$ are incompatible with the accepted basicstatements, $T$ is said to have been falsified, and it should be replaced by some new conjecture providing scientists with an as yet untested, but presumably more satisfactory solution to the problem that they are investigating.

The method of conjectures and refutations revolves, unsurprisingly, around the falsifiability criterion, which Popper characterized as the "supreme rule" (2002a [1935/1959], p. 33) of his methodology: all the other rules that he devised follow from it, although not in a strictly logical or deductive way, but rather in the sense that, taken together, they are aimed at guaranteeing that no scientific statement will be protected against falsification. ${ }^{1}$ The falsifiability criterion is, Popper claimed, "a proposal for an agreement or convention" which ought to guide the activity of those who hold dear such values as critical discussion and freedom from dogmatism, and are therefore moved by the desire to tackle "new and unexpected questions, challenging us to try out new and hitherto undreamed-of answers" (2002a [1935/1959], p. 15). Therefore, in The logic of scientific discovery Popper put forward his first theory of progress, according to which science pursues an "infinite yet attainable aim: that of ever discovering new, deeper

\footnotetext{
${ }^{1}$ Besides openly acknowledging the prescriptive character of his methodological rules, Popper insisted on the descriptive adequacy of the method of conjectures and refutations, i.e., on the fact that it captures the best practice of great scientists. For a discussion of some problems facing Popper's view of methodology, see e.g., Preston (1994).
} 
and more general problems, and of subjecting our ever tentative answers to ever renewed and ever more rigorous tests" (2002a [1935/1959], p. 281). Or, as he more concisely put it in "The aim of science," scientific inquiry is after "satisfactory explanations, of whatever strikes us as being in need of explanation" (1957, p. 24). Scientific progress is thus a matter of finding better and better explanations, that is, corroborated theories of ever greater generality, exhibiting increasing explanatory and predictive power: "a theory that has been well corroborated can only be superseded by one of a higher level of universality" (2002a [1935/1959], p. 276). This means that, within a progressive series of theories, each successive theory is better testable-it has more empirical content-, deals with deeper problems than the previous one, and "contains the old, well corroborated theory-or at least a good approximation to it" (2002a [1935/1959], p. 276).

As mentioned above Popper maintained that, based on the tests which it survived, an unfalsified theory can be viewed as the best among its competitors, and therefore worth of selection for further critical discussion, but in spite of a theory's success in withstanding severe tests, one can never conclude that it is true: once the ideal of demonstrably certain knowledge has been dispensed with, and a thoroughly fallibilist stance has been embraced, all scientific statements come to be viewed as "tentative for ever" (2002a [1935/ 1959], p. 280). In fact, the test of a theory consists in the comparison of the predictions deduced from it with a set of basic-statements, which the scientific community tentatively accepts as descriptions of certain aspects of the world; therefore a theory that has passed a test is said to be corroborated not in any absolute sense, but only with respect to the relevant set of basic-statements. Consequently, what Popper called the 'degree of corroboration' of a theory is to be viewed as nothing but a summary of the current state of the critical discussion concerning the merits of the theory, which comes with a subscript attached, characterizing "the system of basic statements to which the corroboration relates (for example, by the date of its acceptance)" (2002a [1935/1959], p. 275). In this regard, Popper openly remarked that within his theory of science, the concepts 'true' and 'false' are dispensable (2002a [1935/1959], p. 273) - and indeed, until "The aim of science" (1957), he studiously avoided talk of truth when discussing axiological issues.

Popper would later claim that it was only thanks to the work of Alfred Tarski that his hesitation to speak of 'truth' and 'falsity' was swept away. If Popper's recollections in this regard can be relied upon, not long after the completion of the German edition of The logic of scientific discovery, Tarski explained to him "(in the Volksgarten in Vienna) the idea of his definition of the concept of truth" as correspondence to the facts, and he immediately "realized how important it was, and that he had finally rehabilitated the much maligned correspondence theory of truth" (2002b [1974], p. 112; see also 2002a [1935/1959], p. 273, fn. *1). However, it was only between the end of the 1950s and the beginning of the 1960s that Popper put forward his second theory of progress, i.e., the theory of progress as increasing approximation to the truth. More specifically, in Conjectures and refutations he devised an explication of the notion of verisimilitude, or equivalently, truthlikeness (see 1963, pp. 231-234 and 391-397). Based on such explication, he declared that "we simply cannot do without something like this idea of a better or worse approximation to truth" (1963, p. 232), since what we want to say when a theory $T_{2}$ replaces a theory $T_{1}$ is that $T_{2}$ corresponds to the facts better than its predecessor. For instance, such a theory-change as the transition from Newton's to Einstein's theory can be regarded as progressive because, although the new theory is, strictly speaking, presumably false (if only because it involves the use of idealizing assumptions), it is, by our lights, closer to the truth than the superseded one. As Popper later put it in Objective knowledge, "while we can never have sufficiently good arguments in the empirical sciences for claiming that we have actually reached the truth, we can have strong and reasonably good arguments for claiming that we may have made progress towards the truth" (1972, pp. 57-58). The main cognitive aim of scientific inquiry is then characterized, within Popper's second theory of progress, as increasing approximation to the truth: "In the search for knowledge, we are out to find out true theories, or at least theories which are nearer than others to the truth" (1963, p. 226), where following Tarski, truth is construed as correspondence to the facts. $^{2}$

Popper hastened to add that one has to distinguish between the logical problem of verisimilitude, which consists in providing a definition of verisimilitude such that a comparison of any two theories with respect to their closeness to the, supposedly known, truth is possible, and the epistemic problem of verisimilitude, which consists in devising a method to assess the degree of verisimilitude of theories based on the available evidence. Concerning the former problem, Popper believed that his explication solved it; concerning the latter, he claimed to have already solved it in The logic of scientific discovery: the method of conjectures and refutations, he argued, constitutes "the proper methodological counterpart" (1963, p. 235) to the idea of verisimilitude.

For our present purposes it needs to be noted, first of all, that although Popper claimed that his old methodology remained in place unaltered, following the introduction of his new theory of progress, the rules of the method of conjectures and refutations required at least some reinterpretation. In fact, according to Popper's first theory of progress, a scientific community that aims at finding corroborated theories of ever greater explanatory and predictive power ought to select for further critical discussion, among competing unfalsified theories, the more corroborated theory exhibiting the greater explanatory and predictive power. In other words, according to the theory of science defended in The logic of scientific discovery, merely playing the game of science by its rules suffices, in a sense, to reach the aim of the game, given that one cannot draw any sharp distinction between the aim pursued and the means used to pursue it. Not that coming up with conjectures possessing the desired features is a mechanical task: quite on the contrary, Popper declared that "every discovery contains 'an irrational element,' or 'a creative intuition,' in Bergson's sense" (2002a [1935/1959], p. 8), and acknowledged that good theories are anything but easy to come by. In any case, when in Conjectures and refutations Popper put forward his second theory of progress, the question arose whether the falsificationist rules of method are good means for pursuing the aim of approximation to the truth, and more specifically, whether a link between a theory's high degree of corroboration and its possessing a high degree of verisimilitude can be shown to obtain (a question that Imre Lakatos, 1978 [1974] and Adolf Grünbaum, 1976, among others, answered in the negative). While relentlessly defending his methodology, Popper sometimes issued contradictory statements in this regard. To mention but two examples, in a 1972 Addendum to The logic of scientific discovery he emphatically denied that the degree of corroboration is a measure

\footnotetext{
${ }^{2}$ Notoriously, Popper downplayed the differences between his two theories of progress, claiming that Tarski's theory of truth contributed to clarify his views on science and its philosophy but did not change them significantly (2002a [1935/ 1959], p.273, fn. $\left.{ }^{*} 1\right)$. Nevertheless, as our discussion here shows, the theory of progress as increasing approximation to the truth, anything but implicit in The logic of scientific discovery, makes claims concerning the aim of scientific inquiry that Popper's first theory of progress does not make and faces problems that cannot arise within the context of the theory of progress as increasing explanatory power, such as that of the alleged link between corroboration and verisimilitude. For a classical discussion of the problems facing Popper's second theory of progress see Dilworth (2007), esp. chap. 5
} 
of verisimilitude (2002a [1935/1959], p. 282), while in the reply to critics that he prepared for the volume of The library of living philosophers devoted to his work he admitted: "I did suggest in Conjectures and Refutations, Chapter 10, that the degree of corroboration may be taken as an indication of verisimilitude" (1974, p. 1011).

Secondly, despite Popper's confidence, in 1974 his explication of verisimilitude was proven inadequate: based on it, a false theory can never be closer to the truth than another (true or false) theory, so that the Popperian notion of verisimilitude turned out to be inapplicable to the comparison between false theories (see Miller, 1974; Tichý, 1974) — that is, in the scientifically most interesting cases. Indeed, such an inadequacy of Popper's explication put once again under the spotlight what Lakatos always took to be-independently of the problems of Popper's notion of verisimilitude-the major weakness of the methodology of conjectures and refutations, that is, its inability to account for the fact that scientists deal all the time with already falsified theories. When a theory shows enough promise, Lakatos argued, the scientific community behaves in a clearly non-falsificationist way and, contrary to Popper's recommendations, does not treat known counterexamples as reasons to get rid of it: "Some of the research programmes now held in highest esteem by the scientific community progressed in an ocean of anomalies" (Lakatos 1978 [1974], p. 147). ${ }^{3}$

The issues that arose following the introduction of Popper's second theory of progress, however, need not concern us further. What matters here is, rather, that in spite of the technical difficulties encountered by his approach to verisimilitude, Popper continued to stress the importance of the intuitive idea of approximation to the truth as the regulative ideal of scientific inquiry. As we shall see in Section 4, Popper's intuitions in this respect clashed with those of Feyerabend, who from 1965 onwards embraced the very peculiar view that knowledge is "an everincreasing ocean of alternatives" (1981c [1965], p. 107) which do not converge towards the truth; as we shall show, such a view goes hand in hand with Feyerabend's defense of theoretical pluralism, which originated within the context of Popper's views on theory testing. ${ }^{4}$

\section{Feyerabend on theory testing and proliferation}

Throughout all of his career, Feyerabend passionately advocated theoretical pluralism, which he supported by means of various strategies. For instance, one of his favorite lines of argument always was to insist that the proliferation of alternatives to the accepted point of view is desirable since it promotes the full flourishing of human faculties, and he often contrasted such an advantage of pluralism with the narrow-mindedness resulting from the exclusive commitment to one paradigm that characterizes, among others, the Kuhnian scientist (see, e.g., 1970, as well as Lloyd's 2000 [1997] insightful discussion). Moreover, especially from the 1970 s

\footnotetext{
${ }^{3}$ Since 1975, various theories of verisimilitude based on explications of the notion that avoid the flaws of Popper's approach have been proposed (see, e.g., Kuipers, 1987, 2000; Niiniluoto, 1987; Oddie, 1986; and see Oddie, 2014 for a survey of these post-Popperian theories of verisimilitude). Post-Popperian verisimilitude theorists as Kuipers and Niiniluoto have developed non-falsificationist methodologies based on the insight that a falsified theory may well be the closest to the truth among the available alternatives.

4 As pointed out by an anonymous reviewer, Feyerabend seems to have explicitly denied any link between corroboration and verisimilitude as early as 1962 , in a passage of "Explanation, reduction and empiricism" which was removed in the 1981 reprint of this essay in his Philosophical papers: "Even the stability of a testable hypothesis cannot be regarded as a sign of factual truth. [...] There is no sign by which factual truth may be recognized" (1962b, p. 70, fn. 86).
}

onwards, he forcefully disputed the claim that modern science is the only-or the best-way to investigate the world. Non-scientific approaches or traditions, Feyerabend argued, allow their practitioners to acquire valuable insights into the workings of nature: his call for pluralism extended well beyond the realm of scientific inquiry (see especially Farewell to reason, 1987, and the materials collected in the posthumous, unfinished Conquest of abundance, 1999a). In any case, the backbone of Feyerabend's advocacy of proliferation within science was provided by an argument which he put forward in the early 1960s and proposed time and time again, until the end of his career. The argument, aimed at establishing that absent proliferation, severe testing of theories is impossible, starts with an attack against "the assumption of the relative autonomy of facts, or the autonomy principle" (1999b [1963], p. 91).

According to such principle, the facts which constitute the empirical content of a certain theory $T$ are available to the scientific community independently of the consideration of alternatives to $T$. In Feyerabend's view, the principle underlies a monistic model of theory testing characterized by the claim that "a single theory is compared with a class of facts (or observation statements) which are assumed to be 'given' somehow" (1999b [1963], p. 91). The monistic model, Feyerabend argued, is fatally flawed, since it leads to neglect that facts and theories exhibit a much more intimate connection:

Not only is the description of every single fact dependent on some theory (which may, of course, be very different from the theory to be tested). There exist also facts which cannot be unearthed except with the help of alternatives to the theory to be tested, and which become unavailable as soon as such alternatives are excluded (1999b [1963], pp. 91-92).

In other words, in order to severely test a theory $T$, it is not enough to consider the empirical consequences of $T$ and the available evidence: some facts which may refute $T$ can only be discovered by deploying at least one alternative $T^{\prime}$ to $T$. Therefore, Feyerabend argued, the monistic model-which he viewed as "clearly implied in almost all investigations which deal with questions of confirmation and test" (1999b [1963], p. 91) - ought to be replaced with a pluralistic model of theory testing, revolving around the following maxim: "The methodological unit to which we must refer when discussing questions of test and empirical content is constituted by a whole set of partly overlapping, factually adequate, but mutually inconsistent theories" (1999b [1963], p. 92).

Notoriously, the thesis that certain shortcomings of a theory can be revealed only by using alternatives to it has commanded a great deal of critical attention, and in most cases commentators have doubted the viability of Feyerabend's defense of theoretical pluralism (see esp. Farrell, 2003, chap. 5, and Preston, 1997, chap. 7, for extended discussions of the relevant literature). Here, however, we shall not address the merits of Feyerabend's argument for proliferation. Rather, we shall aim at emphasizing, first of all, how deeply rooted such argument was in the Popperian framework; and secondly, how far Feyerabend pushed the argument away from Popper's ideas on theory testing.

Both before and after his break with Popper, Feyerabend admitted that Popper's work provided the starting point of his own investigations. In this regard it is interesting to mention, first of all, that as Matteo Collodel forcefully argues (forthcoming, esp. fn. 31), the very language used by Feyerabend to couch his criticism of the monistic model of theory testing-as well as of the accounts of explanation and reduction favored by the Logical Empiricists-exhibits what seems to be a distinctively Popperian pedigree. For instance, in the opening sentence of his classical "Explanation, reduction and empiricism," Feyerabend declared that his criticism was intended to apply to the test of theories exhibiting a very high level of generality (such as, for instance, Newton's theory), to which 
he referred as "noninstantial theories" (1962b, p. 28 and fn. 1); 'noninstantial theory' and germane expressions, while absent from the vocabulary of Logical Empiricism before Ernest Nagel imported them in (1961), were used in the Popperian circle in the 1950s. Secondly, as Karim Bschir (forthcoming, Sect. 1) has pointed out, although commentators have in many cases taken for granted that, according to Feyerabend, Popper figured prominently among the proponents of the monistic model, "there is hardly any passage in Feyerabend where he associates Popper with the monistic model" of theory testing, for the very good reason that, as his pupil Feyerabend was aware, Popper did not put forward such a model. And indeed, as is well-known, in a passage of "Explanation, reduction and empiricism" which Feyerabend removed when his earlier essays were collected in the two volumes of the Philosophical papers (1981a; 1981b), he credited Popper with being the first to point out "the need, in the process of the refutation of a theory, for at least another theory" (1962b, p. 32). It seems difficult to overestimate Popper's influence on Feyerabend's argument in defense of pluralism, and in what is, to date, the most wide-ranging investigation on the compatibility between Feyerabendian theoretical pluralism and Popperian critical rationalism, Bschir has persuasively argued that Feyerabend's ideas on theory proliferation "must be seen as an extension of certain ideas that Karl Popper had already formulated in his Logic of Scientific Discovery" (forthcoming, Sect. 1).

To our mind, the keyword in the passage just quoted is certainly 'extension.' For, as Bschir openly acknowledges, Feyerabend quickly moved away from Popper's ideas on theory testing.

In this regard one must recall, first of all, that according to Popper the distinctive feature of scientific theories lies in their having empirical content, which guarantees that experience can prove them false. Besides unhesitatingly seconding Popper in this regard, Feyerabend took one further step and argued that empiricism requires the increase of the empirical content, and therefore of the testability, of the accepted theory $T$ via the proliferation of as many alternatives as possible: "the basic principle of empiricism" he claimed, prescribes "to increase the empirical content of whatever knowledge we claim to possess" (1962b, p. 66; see also, e.g., 1999b [1963], p. 93). Popper, on his part, did not take the empirical content of a theory $T$ to be something that depends on the alternatives to $T$, and therefore never explicitly recommended the increase of the number of alternatives to $T$ as a way of maximizing its testability (on this, see esp. Bschir, forthcoming, Sect. 4.1; Worrall, 1978). Thus, Feyerabend pushed to the extreme Popper's lesson that theories are not appraised by comparing them to brute facts, but rather, to the so-called 'basic-statements,' i.e., linguistic entities purporting to describe certain aspects of the world. More precisely, in The logic of scientific discovery Popper argued that a theory is considered as falsified only if the scientific community accepts basic-statements contradicting the predictions that have been deduced from it, and such basic-statements describe some "reproducible effect" (2002a [1935/1959], p. 66): a falsification takes place when the community comes to accept a certain kind of low-level empirical hypothesis which Popper labeled "falsifying hypothesis" (2002a [1935/1959]). This means that the potential falsifiers of scientific theories are in fact, according to Popper, other theories; and as John Preston (1997, p. 134) pointed out, Feyerabend saw no reason to restrict the pool of candidate falsifying hypotheses to low-level ones: rather, he believed that fully fledged, high-level theories provide the best means to severely test the theory that

\footnotetext{
${ }^{5}$ Feyerabend added: "As far as I am aware, this point has been made previously by K. R. Popper in his lectures on scientific method which I attended in 1948 and 1952" (1962b, p. 32, fn. 9).
}

happens to be accepted at a given time. Based on his construal of the notions of empirical content and potential falsifier, Feyerabend went on to champion theory proliferation as no less than "an essential part of the empirical method" (1999b [1963], p. 93) and to put forward the principle of proliferation: "Invent and elaborate theories which are inconsistent with the accepted point of view, even if the latter should happen to be highly confirmed and generally accepted" (1981c [1965], p. 105).

Secondly, after arguing that in order to perform severe theory testing one should use a set of "partly overlapping, factually adequate, but mutually inconsistent theories" (1999b [1963], p. 92; see also 1962b, p. 66), Feyerabend soon relaxed the requirement of factual adequacy. He started Sect. 2 of the essay "Reply to criticism. Comments on Smart, Sellars and Putnam" with the claim that "[n]ot all alternatives are equally suited for the purpose of criticism" (1981c [1965], p. 109), and then articulated a number of strict desiderata that what he called "strong alternatives"-that is, theories which have the potential for displacing their rivals-ought to satisfy. And although Feyerabend did not explicitly blame his former mentor for embracing a naïve form of falsificationism (an accusation which at later stages he was more than happy to make), he went much farther than Popper would have allowed in insisting on the critical role of falsified theories. ${ }^{6}$ In Sect. 1 of the same paper, Feyerabend was adamant in claiming that the principle of proliferation, besides recommending the invention of alternatives to the established view, "prevents the elimination of older theories which have been refuted" (1981c [1965], p. 107), due to the fact that "such theories contribute to the content of their victorious rivals" (1981c [1965], p. 107). Such cases as the history of heliocentrism and of atomism, Feyerabend argued, show that "antediluvian, preposterous ideas [...] may yet be turned against 'modern' views and may even succeed in overthrowing them" (1981c [1965], p. 108). History shows that "things can never be regarded as settled," and that ruling out the "possibility of a "criticism from the past" (1981c [1965], p. 108) would mean to deprive ourselves of an extremely precious resource, since even discredited theories "may be said to possess a 'utopian' component in the sense that they provide lasting, and steadily improving, measuring sticks of adequacy" (1981c [1965], p. 107) for the theories which we now happen to accept. In the first edition of Against method Feyerabend went so far as to explicitly suggest that the condition of factual adequacy of alternatives ought to be "removed" (1975, p. 41, fn. 8), but even absent such an explicit suggestion, it seems quite clear that as early as 1965 he had walked, although not without some hesitations, a long distance from Popper's account of theory testing.

Finally, it is quite surprising that, as Collodel (forthcoming, fn. 31) has pointed out, Popper used the term 'inkommensurabel'-which Popper himself translated into English as "non-comparable" (2002a [1935/1959], p. 98) - as early as 1935, in the German edition of The logic of scientific discovery. However, the term was used by Popper to refer to cases in which the classes of the potential falsifiers of two theories $T_{1}$ and $T_{2}$ intersect but none of the two classes is included in the other, or the two classes have no common elements, so that the falsifiability of $T_{1}$ and $T_{2}$ cannot be compared with the help of the subclass relation. Feyerabend, on his part, employed the notion of incommensurability in "Explanation, reduction and empiricism" within the context of the appraisal of theories. More specifically, he argued against the accounts of explanation and reduction favored by the Logical Empiricists by discussing at length (1962b, pp. 52-60) the relationship between the impetus theory of motion $\left(T_{1}\right)$ and Newtonian mechanics $\left(T_{2}\right)$, i.e., a pair of theories allegedly providing a

\footnotetext{
${ }^{6}$ Such issue will be discussed at length in Section 4 .
} 
paradigm example of such accounts of explanation and reduction. According to Feyerabend's analysis, the deductive relationships that ought to obtain between $T_{2}$ and $T_{1}$ in order for $T_{2}$ to explain $T_{1}$, and for $T_{1}$ to be reducible to $T_{2}$, do not obtain, since the concept of impetus cannot be formulated within the context of Newton's mechanics-and "this is exactly as it should be, considering the inconsistency between some very basic principles of these two theories" (1962b, p. 57). As a consequence, the accounts of explanation and reduction defended by the Logical Empiricists turn out to be inapplicable in the case under consideration. Here, however, it needs to be emphasized that Feyerabend's discussion of such doctrines was aimed not only at exhibiting their descriptive inadequacy, but also at attacking the conceptual conservatism which, he claimed, they promote. In other words, Feyerabend viewed the conceptual change that leads to the incommensurability between certain pairs of theories as a key ingredient for progress. Of course, the emphasis on the importance of conceptual change is anything but extraneous to falsificationism; nevertheless, in the early-to-mid-1960s Feyerabend, unlike Popper, put the notion of incommensurability into the service of the cause of theoretical pluralism (on this, see esp. Oberheim, 2006, chap. 5).

Our discussion above shows that, while originating within an unmistakably Popperian framework, Feyerabend's views on theory testing and proliferation evolved in such a way as to lead him, by the mid-1960s, quite far from Popper's views. Perhaps at first Feyerabend was not entirely clear about how far away he had moved, and it seems that it took him some time to fully appreciate this. In this regard it is worth mentioning that, in the first half of the 1960s, Popper resented Feyerabend for not properly acknowledging that Popper's writings were the actual source of ideas that Feyerabend pretended were his own original contributions (see Collodel, forthcoming, Sect. 2.2.2). And although in a note to the first paragraph of "Reply to criticism. Comments on Smart, Sellars and Putnam" Feyerabend claimed that he was "not aware of having produced a single idea that is not already contained in the realistic tradition and especially in Professor Popper's account of it," solemn acknowledgment ought to be viewed also as a friendly gesture resulting from the recommendations made by Lakatos, who in the Autumn of 1964, encouraged by William W. Bartley, III and Joseph Agassi, approached Feyerabend in order to scold him and to "discipline his questionable intellectual conduct" (Collodel, forthcoming). In any case, the mixed standing of Feyerabend's argument for theoretical pluralism has arguably played a major role in producing the continued disagreement between, on the one hand, interpreters who view the early Feyerabend as someone striving to contribute to the development of Popper's research program and, on the other hand, interpreters who argue that as early as the first half of the 1960s he aimed at proposing a theory of science which would eventually displace falsificationism. Settling such a complicated issue is clearly beyond the scope of the present paper. However, we devoted quite some space to what in 1965 Feyerabend had to say on theory testing and proliferation, because his views regarding these issues are wedded to his theory of progress as a steady increase of competing alternatives, which marked a crucial axiological disagreement with Popper, and which will be dealt with in Section 4 .

\section{Feyerabend's theory of progress}

As detailed above, between the end of the 1950s and the beginning of the 1960s Popper put forward his second theory of

\footnotetext{
${ }^{7}$ In the 1981 reprint of the essay contained in Feyerabend's Philosophical papers, the words "and especially in Professor Popper's account of it" were omitted (1981c [1965], p. 104, fn. 1).
}

progress, according to which approximation to the truth is the main cognitive aim of science. Feyerabend, on his part, never accepted the claim that truth, or approximation to the truth, ought to play a regulative role within scientific inquiry (although, as is wellknown, interpreters strongly disagree on the correct interpretation of his attitude towards scientific realism in the early 1960s: see, e.g., Farrell, 2003, chap. 4; Oberheim, 2006, chap. 6; and Preston, 1997, chap. 4). During the 1960s Feyerabend became more and more vociferous in his defense of pluralism, which he claimed "must not be regarded as a preliminary stage of knowledge which will at some time in the future be replaced by the Only True Theory," since pluralism is "an essential feature of all knowledge that claims to be objective" (1999b [1963], p. 80). By the mid-1960s, wedded to his views concerning theory testing and proliferation was the theory of progress as a steady increase of competing alternatives, from which an 'oceanic' view of knowledge stemmed: according to Feyerabend, knowledge

is not a process that converges towards an ideal view; it is an ever-increasing ocean of alternatives, each of them forcing the others into greater articulation, all of them contributing, via this process of competition, to the development of our mental faculties. All theories, even those which for the time being have receded into the background, may be said to possess a 'utopian' component in the sense that they provide lasting, and steadily improving, measuring sticks of adequacy for the ideas which happen to be in the centre of attention (1981c [1965], p. 107).

In a note to this passage in which he used the Austrian poet's Ingeborg Bachmann words in order to challenge her views concerning the contrast between science and literature, Feyerabend added that science "is an open domain," because "its whole past intrudes into the present" (1981c [1965], fn. 13). Although Feyerabend did not often discuss explicitly such view of progress and knowledge, he endorsed it for a significantly long time-indeed, the importance of the "criticism from the past" (1993, p. 35) is glorified in all the three editions of Against method $(1975,1988,1993)$, in which the exact same points made above are reiterated and expanded, with some differences in wording. ${ }^{8}$ It is important to realize how radical Feyerabend's views are. In fact, although Feyerabend acknowledged that, typically, a scientific controversy comes to an end with the victory of one of the competing alternatives, such a victory has to be viewed, according to his theory of progress, as an only temporary outcome: science is in fact a battlefield where alternatives perpetually clash with each other, and none of them ever prevails on its adversaries once and for all. ${ }^{9}$

Unsurprisingly, Feyerabend's theory of progress-and the view of knowledge stemming from it-attracted harsh criticism. To mention but one example, Hilary Putnam polemically defined "curious" the claim which he took to be "the central contention of Feyerabend's papers," i.e., the claim that, instead of aiming at correct explanations of phenomena, scientists ought to strive for

\footnotetext{
8 As an anonymous reviewer pointed out, the claim-central to Feyerabend's stance-that refuted theories contribute to the content of their victorious rivals seems to be a central feature of the view of science defended by Duhem, whom Feyerabend often mentioned among his heroes.

9 Note that Feyerabend introduced the expression "ocean of alternatives" in 1965 , but he had already argued for the claims that undergird such view of knowledge and progress in previous writings, especially "Explanation, reduction and empiricism" (1962b) and "How to be a good empiricist" (1999b [1963]). Feyerabend discussed at length his view of science as an enterprise characterized by the coexistence of mutually incompatible theories especially in "Consolations for the specialist" (1970), Sect. 6.
} 
"alternative explanations by means of false theories," so that progress does not consist in convergence to the truth but, rather, in entertaining a plurality of theories which "will later turn out to be false, and will be superseded by new batteries of false theories" (1975 [1965], p. 119). In any case, in what follows we shall gloss over the problems facing Feyerabend's views, and focus instead on the compatibility of his theory of progress with Popper's philosophy of science.

Let us start by noting that Popper's first theory of progress and Feyerabend's theory of progress exhibit a clear structural identity, since in both cases a substantial identity between the method and the aim of scientific inquiry is defended: just like Popper recommended the choice of corroborated theories of ever greater explanatory and predictive power as a method serving the purpose to get corroborated theories of ever greater explanatory and predictive power, so from 1965 onwards Feyerabend recommended the proliferation of alternatives as a method serving the purpose of the proliferation of alternatives. As mentioned above, although Feyerabend initially claimed that a severe test of any theory $T$ requires the proliferation of a set of partially overlapping, factually adequate, but mutually inconsistent theories, he later relaxed-and in the end entirely relinquished-the requirement of factual adequacy: all alternatives, he claimed, have a right to participate in the game of science, since the retention of now discredited theories is an essential ingredient of objective knowledge. As Feyerabend put it in 1965, his principle of proliferation, besides recommending the invention of alternatives to the established view, "prevents the elimination of older theories which have been refuted" (1981c [1965], p. 107).

In other words, by the mid-1960s Feyerabend took the principle of proliferation to entail what he would later call the "principle of tenacity," dictating that one ought to stick to a promising theory "despite considerable difficulties" (1999c [1968], p. 107). At first, the idea underlying the principle of tenacity looks very sensible-even trivial perhaps, since after all, the difficulties facing a newly introduced theory may well turn out to be opportunities, for such theory, to unleash its full potential. However, Feyerabend studiously refrained from specifying under what conditions the defense of a theory in the face of known difficulties becomes unreasonable, and the scientist's tenacity turns into sheer stubbornness. Feyerabend often insisted that one should take refutations seriously and that no part of our knowledge ought to be viewed as unrevisable; on one rather isolated occasion, he went so far as to embrace what Lakatos termed "instant rationality" (1978 [1974], p. 149) and to claim that a theory must be "abandoned as soon as a test does not produce the predicted result" (1962b, pp. 29-30). Nevertheless, nothing like a principle of elimination is defended in his writings, specifying under what conditions a theory ought to be excluded from the game of science.

The axiological stance that Feyerabend introduced in "Reply to criticism. Comments on Smart, Sellars and Putnam" is at crosspurposes with the basic insight of falsificationism: the latter always revolved around the view that scientists learn by discarding theories which experience has shown to be faulty, the former has been aptly defined as the advocacy of an "extremely cumulativist account of science" (Niiniluoto, 1999, p. 294). And yet the axiological disagreement that, we suggest, contributes to explain Feyerabend's changing attitude towards falsificationism was due not only to his radicalizing understanding of theoretical pluralism, but also to Popper's evolving views on the aim of science. Before the theory of progress as approximation to the truth was introduced, within the falsificationist framework there was quite some room for someone wishing to explore the possibility of amendments to Popper's doctrines such as some of those proposed by Feyerabend in his writings. ${ }^{10}$ For instance, as Bschir (forthcoming) argues at length, in spite of the later Feyerabend's vocal criticisms of Popper, Feyerabendian theoretical pluralism and Popperian critical rationalism are closer than has generally been acknowledged, and the former can be viewed as an extension of the latter. More generally, it seems to us that before the introduction of Popper's second theory of progress, the situation within falsificationist philosophy of science was a bit less straightforward than Popper was willing to admit.

Famously, Popper repeatedly claimed that his methodological proposals stem from the recognition of the asymmetry between falsifiability and verifiability: universal statements, he emphasized, "are never derivable from singular statements, but can be contradicted by singular statements" (2002a [1935/1959], p. 19), so that a well-established theory can be overthrown by singular statements contradicting the predictions derived from the theory. In spite of his insistence on such asymmetry-which he advertised as one of the main reasons why the methodology of conjectures and refutations is by far superior to its inductivist rivals-Popper also had to admit that "no conclusive disproof of a theory can ever be produced" (2002a [1935/1959], p. 28), since all scientific statements are susceptible to revision. Recall, in this regard, what we said above concerning the theoretical character of potential falsifiers, as well as concerning the temporal subscript that-ideally at least-comes attached to the assessment of the degree of corroboration of a theory, and that characterizes the set of basic statements tentatively accepted by the scientific community "to which the corroboration relates (for example, by the date of its acceptance)" (2002a [1935/1959], p. 275).

One way to look at the theory of progress and knowledge that Feyerabend put forward in 1965 is then to consider it as an overextension of Popperian ideas concerning theory testing, the theoryladenness of observation, and the permanently tentative character of scientific statements. And indeed, a long-standing interpretative tradition maintains that Feyerabend's trajectory must be viewed as nothing but the result of "his change to a radically sceptical interpretation of Popper's own philosophy of science" (Lakatos, 1978 [1974], p. 166, fn. 2) - a change leading to what John McEvoy (1975), for one, unhesitatingly dismissed as a "degeneration." Be that as it may, here we need to emphasize that, as long as the theory of progress as increasing explanatory power was officially in place, much of what Feyerabend defended was entirely compatible with a falsificationist outlook. Of course, when Feyerabend proposed his own theory of progress as a steady increase of competing alternatives, he decidedly stepped out of the Popperian orthodoxy. But such orthodoxy had, in turn, significantly changed, since after advocating a view of science in which "it is possible to avoid using the concepts 'true' and 'false”" (2002a [1935/1959], p. 273), Popper put forward the theory of progress as approximation to the truth. It would perhaps have been possible, for Feyerabend, to defend his theory of progress while maintaining an at least loose allegiance to a (broadly conceived) Popperian framework, as long as the latter did not entail any commitment concerning approximation to the truth as the main cognitive aim of science; following the introduction of Popper's second theory of progress, Feyerabend's views could no longer be made compatible with the Popperian framework, no matter how broadly conceived. Popper's changing views on the aim of science, we suggest, are an underestimated factor that contributes to explain Feyerabend's changing attitude towards falsificationism.

\footnotetext{
10 This is not meant to suggest that in the early 1960s Feyerabend's main aim was to contribute to the development of Popper's research program: as mentioned above, this is an issue on which interpreters strongly disagree, and on which we shall remain neutral here.
} 


\section{Concluding remarks}

In this paper, based on the analysis of the theories of progress and the aim of science put forward by Popper in The logic of scientific discovery and Conjectures and refutations (Sect. 2) and by Feyerabend in "Reply to criticism. Comments on Smart, Sellars and Putnam" (Sect. 3 and Sect. 4), we argued that Popper's changing views on the aim of science constitute an underestimated factor that contributes to account for Feyerabend's changing attitude towards falsificationism. However, not for a moment do we mean to imply that Popper's proposing the theory of progress as increasing approximation to the truth provides the explanation of Feyerabend's more and more vociferous criticism of Popperian philosophy of science-indeed, we doubt that one such explanation is possible, and this for at least three reasons.

First of all, the Feyerabend-Popper relation was a long-term, multifaceted one, that involved intertwined intellectual and personal issues-on which, as is well-known, Feyerabend returned time and time again in various writings (especially in Killing time, 1996), providing sometimes conflicting, and sometimes unreliable, reports.

Secondly, and consequently, even when the attention is restricted to purely intellectual matters, things are in any case complicated: perhaps due to the fact that it took Feyerabend some time to fully appreciate how far away he had moved from the Popperian orthodoxy, interpreters must deal with a somewhat twisted storyline. For instance, thanks to Collodel's work (forthcoming) we now know that, at the end of the 1950s, Feyerabend himself suggested to Popper the idea of a collection of his most recent papers, thereby playing a role in bringing about the publication of Conjectures and refutations, which Feyerabend volunteered to review. In a more than enthusiastic, and less than one page long piece, published in Isis, he concealed any disagreement with his former mentor and hailed the book as "a major contribution to philosophy [...] whose publication constitutes a major event in the history of this subject" (1965, p. 88). Indeed, it is difficult to imagine a more unhesitating endorsement of Popper's philosophy than the one witnessed by this review; and yet, in 1965 Feyerabend was advocating a theory of progress which is incompatible with that introduced in Conjectures and refutations.

Thirdly, and to our mind more importantly, Popper's philosophy is a complex system of ideas, and depending on the specific aspect of such system on which one decides to focus, Feyerabend may look closer to, or farther from, his former mentor. To briefly mention but one example concerning the later Feyerabend's output, Preston has contended that it was due to his Popperian legacy that Feyerabend chose to attack methodological monism-according to which there is one set of rules of method underlying all good scientific practice-in the way he did: by exhibiting historical cases in which progress has been achieved despite the violation of rules. Feyerabend's criticism of monism, Preston suggests, crucially relies on the assumption that rules must be exceptionless deductive ones: in this regard, the Feyerabend of Against method turns out to be "a Popperian deductivist manqué" (1997, p. 174), since just like Popper, whose characterization of the proper method of science he vehemently criticized, he denied the possibility of an inductive justification of rules. If Preston's suggestion is correct, then the later Feyerabend was, in this respect, much closer to Popper than he would have liked to admit.

Nevertheless our discussion suggests that, when it comes to axiological issues, as early as 1965 Feyerabend's philosophy evolved in such a way as to be incompatible with Popper's second theory of progress. In this regard our account contradicts, for instance, Robert Farrell's claim that Feyerabend always "remained a faithful Popperian" in that he believed "that the aim of science consists in critical explanatory progress" (2003, p. 156). Although Popper always maintained that the method of conjectures and refutations, recommending the choice of ever more general, explanatory theories, promotes progress, starting from the late 1950s-early 1960s he characterized the aim of science as approximation to the truth. And when the attempt is made to explain Feyerabend's disavowal of falsificationism, an accurate account ought to include not only Feyerabend's move away from Popper's views, but also Popper's move away from his own originary views.

\section{Acknowledgments}

Thanks are due to Karim Bschir for providing me with an advanced version of his forthcoming essay on the compatibility of Feyerabend's theoretical pluralism and Popper's critical rationalism, as well as to Gustavo Cevolani, Matteo Collodel, Roberto Festa, and two anonymous reviewers for their insightful comments on previous versions of the present paper. Usual disclaimers apply. Financial support from PRIN grant (20122T3PTZ) Models and Inferences in Science is gratefully acknowledged.

\section{References}

Bschir, K. (2015). Feyerabend and Popper on theory proliferation and anomaly import: On the compatibility of theoretical pluralism and critical rationalism. HOPOS. The Journal of the International Society for the History of Philosophy of Science (forthcoming)

Collodel, M. (2015). Was Feyerabend a Popperian? Methodological issues in the history of the philosophy of science. Studies in History and Philosophy of Science (forthcoming)

Dilworth, C. (2007). Scientific progress. A study concerning the nature of the relation between successive scientific theories (4th ed.). Berlin-New York: Springer.

Farrell, R. P. (2003). Feyerabend and scientific values. Tightrope-walking rationality. Dordrecht: Kluwer.

Feyerabend, P. K. (1962a). Knowledge without foundations. Two lectures delivered on the Nellie Heldt lecture fund. Oberlin (Oh.): Oberlin College.

Feyerabend, P. K. (1962b). Explanation, reduction and empiricism. In H. Feigl, \& G. Maxwell (Eds.), Scientific explanation, space and time (pp. 28-97). Minneapolis: University of Minnesota Press.

Feyerabend, P. K. (1965). Review of K. R. Popper, Conjectures and refutations. Isis, $56,88$.

Feyerabend, P. K. (1970). Consolations for the specialist. In I. Lakatos, \& A. Musgrave (Eds.), Criticism and the growth of knowledge (pp. 197-230). Cambridge: Cambridge University Press.

Feyerabend, P. K. (1975). Against method: Outline of an anarchistic theory of knowledge. London: New Left Books.

Feyerabend, P. K. (1981a). Realism, rationalism and scientific method. Philosophical papers, Vol. 1. Cambridge: Cambridge University Press.

Feyerabend, P. K. (1981b). Problems of empiricism. Philosophical papers, Vol. 2. Cambridge: Cambridge University Press.

Feyerabend, P. K. (1981c [1965]). Reply to criticism. Comments on Smart, Sellars and Putnam. In P. K. Feyerabend, Realism, rationalism and scientific method. Philosophical papers, Vol. 1 (pp. 104-131). Cambridge: Cambridge University Press. Originally published in R. S. Cohen, \& M. W. Wartofsky (Eds.), Proceedings of the Boston colloquium for the philosophy of science 1962-1964: In honor of Philipp Frank (pp. 223-261). New York: Humanities Press, 1965.

Feyerabend, P. K. (1987). Farewell to reason. London: Verso.

Feyerabend, P. K. (1988). Against method (2nd ed.). London: Verso.

Feyerabend, P. K. (1993). Against method (3rd ed.). London: Verso.

Feyerabend, P. K. (1996). Killing time. An autobiography. Chicago: The University of Chicago Press.

Feyerabend, P. K. (1999a). Conquest of abundance. A tale of abstraction versus the richness of Being, edited by B. Terpstra. Chicago: The University of Chicago Press.

Feyerabend, P. K. (1999b [1963]). How to be a good empiricist. A plea for tolerance in matters epistemological. In P. K. Feyerabend, Knowledge, science and relativism. Philosophical papers, Vol. 3, edited by J. Preston (pp. 78-103). Cambridge: Cambridge University Press. Originally published in B. Baumrin (Ed.), Philosophy of science: the Delaware seminar (pp. 3-39). New York: Interscience Press, 1963.

Feyerabend, P. K. (1999c [1968]). Outline of a pluralistic theory of knowledge and action. In P. K. Feyerabend, Knowledge, science and relativism. Philosophical papers, Vol. 3, edited by J. Preston (pp. 104-111). Cambridge: Cambridge University Press. Originally published in S. Anderson (Ed.), Planning for diversity and choice (pp. 275-284). MIT Press: Cambridge, 1968.

Grünbaum, A. (1976). Is the method of bold conjectures and attempted refutations justifiably the method of science? The British Journal for the Philosophy of Science, 27, 105-136.

Hoyningen-Huene, P., \& Oberheim, E. (2000). Feyerabend's early philosophy. Studies in History and Philosophy of Science, 31, 363-375. 
Kuipers, T. A. F. (1987). A structuralist approach to truthlikeness. In T. A. F. Kuipers (Ed.), What is closer-to-the-truth? (pp. 79-99). Amsterdam: Rodopi.

Kuipers, T. A. F. (2000). From instrumentalism to constructive realism. Dordrecht: Kluwer.

Lakatos, I. (1978 [1974]). Popper on demarcation and induction. In I. Lakatos, Philosophical papers, Vol. 1: The methodology of scientific research programmes, edited by J. Worrall \& G. Currie (pp. 139-167). Cambridge: Cambridge University Press. Originally published in P. A. Schilpp (Ed.), The philosophy of Karl Popper (pp. 241-273). La Salle, Open Court, 1974.

Lloyd, E. (2000 [1997]). Feyerabend, Mill, and pluralism. In D. Lamb, G. Munévar, \& J. Preston (Eds.), The worst enemy of science? Essays in memory of Paul Feyerabend (pp. 115-124). Oxford: Oxford University Press. Originally published in Philosophy of Science, 64, S396-S407.

McEvoy, J. (1975). A "revolutionary" philosophy of science: Feyerabend and the degeneration of critical rationalism into sceptical fallibilism. Philosophy of Science, 42, 49-66.

Miller, D. (1974). Popper's qualitative theory of verisimilitude. The British Journal for the Philosophy of Science, 25, 166-177.

Nagel, E. (1961). The structure of science. London: Routledge \& Kegan Paul.

Niiniluoto, I. (1987). Truthlikeness. Dordrecht: Kluwer.

Niiniluoto, I. (1999). Critical scientific realism. Oxford: Oxford University Press.

Oberheim, E. (2006). Feyerabend's philosophy. Berlin: de Gruyter.

Oddie, G. (1986). Likeness to truth. Dordrecht: Reidel.

Oddie, G. (2014). Truthlikeness. In E. N. Zalta (Ed.), The Stanford encyclopedia of philosophy (Summer 2014 Edition). http://plato.stanford.edu/archives/ sum2014/entries/truthlikeness/. Retrieved 3rd September 2014

Popper, K. R. (1957). The aim of science. Ratio, 1, 24-35.

Popper, K. R. (1959). Back to the Presocratics. Proceedings of the Aristotelian Society, $59,1-24$.

Popper, K. R. (1963). Conjectures and refutations. London: Routledge \& Kegan Paul.
Popper, K. R. (1972). Objective knowledge. An evolutionary approach. Oxford: Clarendon Press.

Popper, K. R. (1974). Replies to my critics. In P. A. Schilpp (Ed.), The philosophy of Karl Popper (pp. 961-1197). La Salle: Open Court.

Popper, K. R. (2002a [1935/1959]). The logic of scientific discovery. London: Routledge. Originally published as Logik der Forschung. Vienna: Springer, 1935. First English edition: London: Hutchinson, 1959.

Popper, K. R. (2002b [1974]). Unended quest. An intellectual autobiography. Routledge: London. Originally published as Autobiography of Karl Popper. In P. A. Schilpp (Ed.), The philosophy of Karl Popper (pp. 3-181). La Salle: Open Court, 1974.

Preston, J. (1994). Methodology, epistemology and conventions. Popper's bad start. In D. Hull, M. Forbes, \& R. M. Burian (Eds.), PSA 1994. Proceedings of the biennial meeting of the Philosophy of Science Association (Vol. 1, pp. 314-322) East Lansing (Mich.): The Philosophy of Science Association.

Preston, J. (1997). Feyerabend: Philosophy, science and society. Cambridge: Polity Press.

Putnam, H. (1975 [1965]). How not to talk about meaning. In H. Putnam, Philosophical papers, Vol. 2: Mind, language and reality (pp. 117-131). Cambridge: Cambridge University Press. Originally published in R. S. Cohen, \& M. W. Wartofsky (Eds.), Proceedings of the Boston colloquium for the philosophy of science 1962e 1964: In honor of Philipp Frank (pp. 205-222). New York: Humanities Press, 1965.

Tichý, P. (1974). On Popper's definition of verisimilitude. The British Journal for the Philosophy of Science, 25, 155-160.

Watkins, J. (2000). Feyerabend among Popperians, 1948-1978. In D. Lamb, G. Munévar, \& J. Preston (Eds.), The worst enemy of science? Essays in memory of Paul Feyerabend (pp. 47-57). Oxford: Oxford University Press.

Worrall, J. (1978). Is the empirical content of a theory dependent on its rivals? Acta Philosophica Fennica, 30, 298-310. 